\title{
DNA single strand breaks in peripheral lymphocytes associated with urinary thiodiglycolic acid levels in polyvinyl chloride workers
}

\author{
Yu-Chen Lei ${ }^{a}$, Huei-Ting Yang ${ }^{a}$, Yee-Chung Ma ${ }^{b}$, Ming-Feng Huang ${ }^{b}$, \\ Wushou P. Chang ${ }^{\mathrm{c}}$, Tsun-Jen Cheng ${ }^{\mathrm{a}, *}$ \\ ${ }^{a}$ Institute of Occupational Medicine and Industrial Hygiene, College of Public Health, \\ National Taiwan University, No. 1 Ren-Ai Road, Sec. 1, Taipei 10018, Taiwan \\ ${ }^{\mathrm{b}}$ Institute of Environmental Health, College of Public Health, National Taiwan University, No. 1 Ren-Ai Rd., Sec. 1, Taipei, Taiwan \\ ${ }^{c}$ Institute of Environmental Health Science, School of Medicine, National Yang Ming University 155, \\ Li-Nong St., Sec. 2, Peitou, Taipei, Taiwan
}

Received 7 November 2003; received in revised form 15 April 2004; accepted 15 April 2004

Available online 7 June 2004

\begin{abstract}
The association between vinyl chloride monomer (VCM) exposure and DNA damage has been established. However, the relationship between individual exposure and DNA single strand breaks was limited. Since environmental monitoring may not reflect the actual exposure, a useful marker of exposure is needed to assess the individual exposure. In our previous study, we have found a high correlation between air VCM level and urinary thiodiglycolic acid (TdGA) at the commencement of the next shift. Here, we further used comet assay to evaluate the relationship between urinary TdGA levels and DNA single strand breaks in polyvinyl chloride monomer (PVC) workers. Urinary TdGA levels $(n=26)$ at the commencement of the following shift were analyzed. Ten of the 26 workers also had personal air sampling for air VCM exposure. Questionnaires were administered to obtain epidemiological information including detailed history of occupation and lifestyles. Workers experiencing air VCM level greater than $5 \mathrm{ppm}$ had higher tail moment and tail intensity (\%) than those experiencing VCM exposure between 1 and 5 , or $<1 \mathrm{ppm}$, respectively $(P<0.05)$. The results also revealed that level of DNA single strand breaks, including tail moment and tail intensity, were increased with urinary TdGA level. The dose-response relationship of urinary TdGA level and DNA single strand breaks was particularly significant among the workers with $4 \mathrm{mg} / \mathrm{g}$ Cr of urinary TdGA level, which is equivalent to $5 \mathrm{ppm}$ air VCM level. We concluded that air VCM exposure greater than $5 \mathrm{ppm}$ could induce DNA damage. Further sensitive assay should be developed for the diction of DNA damage when air VCM exposure below 5 ppm. (C) 2004 Elsevier B.V. All rights reserved.
\end{abstract}

Keywords: DNA single strand breaks; Urinary thiodiglycolic acid; Vinyl chloride monomer

\footnotetext{
* Corresponding author. Tel.: +886 223957845 ; fax: +886223957845.

E-mail address: tcheng@ha.mc.ntu.edu.tw (T.-J. Cheng).
}

\section{Introduction}

Vinyl chloride monomer (VCM) exposure has been associated with angiosarcoma and hepatocellular cancer [1-3] and classified as a group 1 carcinogen by IARC (1987). Previous epidemiological studies have 
shown that VCM exposure was associated with increased genotoxicity in human studies [4,5]. However, their dose-response relationship of personal VCM exposure and DNA single strand breaks is limited [6]. To further evaluate this relationship, a better exposure assessment and a more sensitive biomarkers of genetic damage are needed.

Because the air level of VCM in the work site is relatively low, environmental monitoring and job titles may not reflect the actual worker exposure level. To make better assessment of individual VCM exposure, thiodiglycolic acid (TdGA) is proposed as a marker of internal dose recently. TdGA is one of the normal products of human metabolism, and occurs at low concentration in urine [7]. A significant increase is observed when the organism is exposed to some physiologically active or toxic substances, including VCM [8-10], 1,2-dichloroethane [11], and vinylidene chloride [12]. Our previous further found that the urinary TDGA level was best detected at the commencement of the next shift and can be used as an exposure marker for VCM exposure [8].

A wide variety of cytogenetic methods have been used as indicators of DNA damage of VCM exposure, including chromosome aberration (CA) [13-15], sister chromatid exchanges (SCEs) $[5,16]$ and micronucleus assay [17]. However, these methods are labor intensive and time consuming. Moreover, the level of DNA damage obtained by visual scoring may result in unexpected bias. Recently, the comet assay has been used popularly in occupational epidemiological studies because of its ease to perform [18]. Studies have indicated that comet assay is a sensitive assay in detecting DNA damage $[19,20]$.

In this study, we used a comprehensive design to investigate the relationship between urinary TdGA and DNA single strand breaks determined by comet assay in peripheral lymphocytes in VCM exposed workers.

\section{Materials and methods}

\subsection{Study population and epidemiological information}

A total of 26 male workers were enrolled from three Taiwanese polyvinyl chloride (PVC) manufac- turing plants. All study subjects were surveyed by an interviewer-administered questionnaire to obtain information pertaining to smoking activity, alcohol consumption, medication taken, and medical and occupational histories subsequent to informed consent having been obtained. A detailed occupational history was compiled for each study subject, this including job title, daily activity within 1 week of sample collection and information regarding whether or not it was normal practice for the worker to use a respirator whilst working. Current smokers were defined as those who had been smoking within a period of 6 months prior to sample collection. Alcohol drinking for a study subject was defined as a person who consumed alcohol on at least one occasion per week.

\subsection{Personal exposure to air VCM}

One measurement per one subject of personal sampling was conducted among 10 of the 26 workers to obtain VCM exposure information using a modification of a method (\#1007) originating from the National Institute for Occupational Safety and Health (NIOSH), USA (1994). Personal air sampling conducted in workers' breathing zones for about $6-7 \mathrm{~h}$ during day working shifts was performed. All subjects were collected at the same day. At the completion of monitoring, all samples were immediately capped and stored at $4{ }^{\circ} \mathrm{C}$. The sample-contained VCM was subsequently extracted with carbon disulfide and analyzed by gas chromatography with mass spectrometry. The VCM-in-air time-weighted average (TWA) for each worker was calculated.

\subsection{Urinary TdGA measurement}

Methodology for urinary TdGA level measurement was described in our previous study [8]. Briefly, urine samples from the 26 study-participating workers were collected at the commencement of the shift on the subsequent day of personal air sampling. Urine samples were stored at $-20^{\circ} \mathrm{C}$ until used for analysis. Five milliliters of collected urine was mixed with $\mathrm{H}_{2} \mathrm{SO}_{4}$ and $\mathrm{NaCl}$, then ethyl acetate was added and the mixture centrifuged. The supernatant was subsequently transferred into another tube to dry. Following this $400 \mu \mathrm{l}$ pyridine and $800 \mu \mathrm{l}$ $\mathrm{N}, \mathrm{N}$-diethyltrimethylsilyamine (TMSA) were added 
to the tube containing the dried supernatant in order to achieve silylation, following which, gas chromatography/mass spectrometer was then used to determine the concentration of TdGA derivatives in the samples. Urinary TdGA concentration was adjusted for urinary creatinine level.

\subsection{Determination of DNA single strand breaks by comet assay}

The alkaline comet assay was used to determine DNA single strand breaks [21]. Peripheral lymphocytes were collected at the commencement of the subsequent shift and were isolated by Ficoll method and stored under $-70^{\circ} \mathrm{C}$. Cells were suspended in Dulbecco's minimal essential medium with 20,000 cells/ml and immediately put on ice. Quantities of $20 \mu \mathrm{l}$ of aliquot of the cell suspension (105 cells $/ \mathrm{ml})$ were mixed with $1 \mathrm{ml}$ of $1.5 \%$ low-melting agarose, and gelled to frosted slides pretreated with $0.1 \%$ normal-melting agarose on ice. After gelling, the slides were immersed in alkaline lysis buffer $(2.5 \%$, SDS and $25 \mathrm{mM}$ EDTA, pH 13) for $10 \mathrm{~min}$, then washed by PBS. They were then placed in buffer ( $30 \mathrm{mM} \mathrm{NaOH}$ and $1 \mathrm{mM}$ EDTA) for electrophoresis at $21 \mathrm{~V}$ and $190 \mathrm{~mA}$ for $20 \mathrm{~min}$. Subsequently, slides were rinsed and stained in Sybr Green. Individual cells were examined under a microscope with a photomicrographic system. All slides were coded and read blindly. The images were then recorded for further image analysis. We also used A549 cells that had been aliquoted previously as an internal standard to adjust for experimental variability [22].

Proprietary image processing software, which has been used in previous studies [22,23], was applied to calculate the distribution of DNA on the agarose. Images of 100 randomly selected cells from each set of the experiment were analyzed under a fluorescence microscope adapted with excitation at 515-560 nm and a barrier filter of $590 \mathrm{~nm}$. Parameters used in the analysis were tail length $(\%)$, tail intensity $(\%)$ and tail moment. Tail length (\%) was defined as the proportion of tail length of the entire comet length; tail intensity (\%) was defined as the proportion of tail intensity of the total comet intensity; and tail moment was defined as the product of tail length and tail intensity. We used the percentage of tail length because of its ease in measurement, as in the measurement of tail intensity [23].

\subsection{Statistical analysis}

Statistical analysis system (SAS) software was used for the statistical analysis. Student's $t$-test was used to compare tail length (\%), tail intensity (\%) and tail moment between different urinary TdGA level and other potential confounding factors. Multiple regression models were used to determine if urinary TdGA and confounding factors were associated with DNA single strand breaks. According to our previous work, the best fit for urinary TdGA on air VCM was $Y=1.06$ $+0.57 X$ for urine collected at the commencement of the following work shift, where $X$ is the air VCM concentration and $Y$ the urinary TdGA concentration [8]. Thus, urinary TdGA of $4 \mathrm{mg} / \mathrm{g} \mathrm{Cr}$ is equivalent to air VCM exposure level of $5 \mathrm{ppm}$. Subsequently, linear regression models were used to perform the association between DNA single strand breaks and urinary TdGA level estimated as air VCM exposure level greater than $5 \mathrm{ppm}$. A $P$-value of less than 5\% was considered significant.

\section{Results}

Basic characteristics of the study population and comet indicators are summarized in Table 1 . The average age of these workers were $42.2 \pm 2.1$ years (mean \pm S.E.). Ten workers had personal air VCM level, and the average VCM level was $3.4 \pm 1.3 \mathrm{ppm}$. The mean urinary TdGA at the commencement of the following work shift was $3.90 .5 \mathrm{mg} / \mathrm{g} \mathrm{Cr}$. The mean tail length (\%), tail intensity (\%) and tail moment among 26 workers were $56.9 \pm 2.9,50.2 \pm 3.0$ and $35.5 \pm$ 3.4 , respectively.

Workers experiencing air VCM exposure $>5 \mathrm{ppm}$ had significantly higher DNA damage than those experiencing low air VCM exposure in tail intensity (\%) and tail moment $(P<0.05)$. Similarly, DNA damage levels were increased with increasing urinary TdGA concentration. The tail length $(\%)$ and tail moment of workers with urinary TdGA greater than $4 \mathrm{mg} / \mathrm{g}$ $\mathrm{Cr}$ were significantly higher than those with urinary TdGA less than $1.5 \mathrm{mg} / \mathrm{g} \mathrm{Cr}(P<0.05)$. Among eight workers having high urinary TdGA level, six $(75 \%)$ workers were current smokers. Among 16 workers having moderate urinary TdGA level, 14 (87\%) workers were current smokers. While, further workers in 
Table 1

Basic characteristics of study subjects and DNA single strand breaks with urinary TdGA and other potential determinants

\begin{tabular}{|c|c|c|c|c|}
\hline Variable & $N(\%)$ & $\begin{array}{l}\text { Tail length } \\
(\%, \text { mean } \pm \text { S.E. })\end{array}$ & $\begin{array}{l}\text { Tail intensity } \\
(\%, \text { mean } \pm \text { S.E. })\end{array}$ & $\begin{array}{l}\text { Tail moment } \\
(\text { mean } \pm \text { S.E. })\end{array}$ \\
\hline Age (years) & & $56.9 \pm 2.9$ & $50.2 \pm 3.0$ & $35.5 \pm 3.4$ \\
\hline$>40$ & $13(50)$ & $54.6 \pm 2.4$ & $47.5 \pm 2.5$ & $31.4 \pm 3.1$ \\
\hline$\leq 40$ & $13(50)$ & $59.3 \pm 2.5$ & $53.0 \pm 2.5$ & $40.0 \pm 3.8$ \\
\hline \multicolumn{5}{|c|}{ Employment duration (years) } \\
\hline$\leq 10$ & $11(42)$ & $59.3 \pm 2.9$ & $53.3 \pm 3.0$ & $39.8 \pm 4.3$ \\
\hline $10-30$ & $10(39)$ & $56.8 \pm 2.9$ & $49.5 \pm 3.0$ & $34.5 \pm 3.6$ \\
\hline$>30$ & 5 (19) & $52.2 \pm 3.0$ & $45.0 \pm 2.5$ & $27.9 \pm 7.1$ \\
\hline \multicolumn{5}{|c|}{ Air VCM level ${ }^{\mathrm{a}}$} \\
\hline High & $2(20)$ & $71.0 \pm 1.8$ & $65.2 \pm 1.0^{*}$ & $61.0 \pm 3.0^{*}$ \\
\hline Moderate & $4(40)$ & $59.7 \pm 0.7$ & $51.7 \pm 0.8$ & $36.0 \pm 2.0$ \\
\hline Low & $4(40)$ & $63.1 \pm 2.8$ & $54.1 \pm 2.1$ & $43.4 \pm 4.4$ \\
\hline \multicolumn{5}{|c|}{ Urinary $\mathrm{TdGA}^{\mathrm{b}}$} \\
\hline High & $8(30)$ & $64.2 \pm 3.9^{*}$ & $56.4 \pm 4.0$ & $46.1 \pm 7.4^{*}$ \\
\hline Moderate & $16(61)$ & $61.3 \pm 2.0$ & $53.8 \pm 2.3$ & $39.8 \pm 4.4$ \\
\hline Low & $2(9)$ & $53.6 \pm 2.2$ & $47.4 \pm 2.5$ & $31.2 \pm 2.9$ \\
\hline \multicolumn{5}{|c|}{ Cigarette smoking } \\
\hline Yes & $20(77)$ & $56.4 \pm 1.7$ & $50.0 \pm 2.0$ & $34.5 \pm 2.5$ \\
\hline No & $6(23)$ & $58.8 \pm 5.3$ & $51.2 \pm 4.8$ & $38.6 \pm 7.5$ \\
\hline \multicolumn{5}{|c|}{ Alcohol consumption } \\
\hline Yes & $11(42)$ & $59.7 \pm 2.2$ & $53.1 \pm 2.2$ & $40.3 \pm 3.9$ \\
\hline No & $15(58)$ & $54.9 \pm 2.5$ & $48.1 \pm 2.7$ & $32.0 \pm 3.1$ \\
\hline \multicolumn{5}{|l|}{ Coffee } \\
\hline Yes & $6(23)$ & $59.7 \pm 2.3$ & $52.3 \pm 1.8$ & $37.1 \pm 3.8$ \\
\hline No & $20(77)$ & $56.1 \pm 2.2$ & $49.6 \pm 2.3$ & $35.0 \pm 3.1$ \\
\hline \multicolumn{5}{|l|}{ Tea } \\
\hline Yes & 18 (69) & $56.7 \pm 1.9$ & $49.9 \pm 2.1$ & $34.7 \pm 2.5$ \\
\hline No & $8(31)$ & $57.5 \pm 4.0$ & $51.0 \pm 4.0$ & $37.1 \pm 6.3$ \\
\hline
\end{tabular}

${ }^{a}$ VCM, vinyl chloride monomer. Air VCM level: high $>5 \mathrm{ppm} ; 1 \mathrm{ppm} \leq$ moderate $\leq 5 \mathrm{ppm}$; low $<1 \mathrm{ppm}$.

${ }^{\mathrm{b}}$ Urinary TdGA level of $4 \mathrm{mg} / \mathrm{g} \mathrm{Cr}$ was equivalent to air VCM of $5 \mathrm{ppm}, 1.5 \mathrm{mg} / \mathrm{g} \mathrm{Cr}$ was equivalent to air VCM of $1 \mathrm{ppm}$. Urinary TdGA level: high $>4 \mathrm{mg} / \mathrm{g} \mathrm{Cr} ; 1.5 \mathrm{mg} / \mathrm{g} \mathrm{Cr} \leq$ moderate $\leq 4 \mathrm{mg} / \mathrm{g} \mathrm{Cr}$; low $<1.5 \mathrm{mg} / \mathrm{g} \mathrm{Cr}$.

${ }^{*} P<0.05$, compared with low group.

low exposure group were non-smokers. However, further analysis showed DNA single strand breaks were not associated with smoking. With stratification, no significant differences between smoking status and the tail length (\%), tail intensity (\%) and tail moment were observed in workers having high or moderate urinary TdGA level. Last, we did not observe any association between DNA single strand breaks and age, alcohol consumption or duration of employment.

To investigate whether other confounders may have effects on single strand breakage, further regression analysis was demonstrated in Table 2. After adjusting for age and smoking status, urinary TdGA was signif- icantly associated with tail intensity $(\%)(P<0.05)$. Urinary TdGA was also borderline significantly associated with tail moment $(P=0.07)$.

In our analysis, DNA damage levels did not differ between moderate and low urinary TdGA groups. Our previous study also indicated that urinary TdGA levels overlapped with each other when air VCM levels were below $5 \mathrm{ppm}$. Therefore, the subsequent analysis was focused on the eight subjects with urinary TdGA greater than $4 \mathrm{mg} / \mathrm{g} \mathrm{Cr}$, which is equivalent to $5 \mathrm{ppm}$ of air VCM. The best fit of the regression of DNA damage on the urinary TdGA level were demonstrated in Fig. 1. Tail moment was associated with urinary 
Table 2

Multiple regression of DNA single strand breaks on urinary TdGA and different confounders

\begin{tabular}{|c|c|c|c|c|c|c|c|c|c|}
\hline \multirow[t]{2}{*}{ Variable } & \multicolumn{3}{|c|}{ Tail length (\%) } & \multicolumn{3}{|c|}{ Tail intensity $(\%)$} & \multicolumn{3}{|c|}{ Tail moment } \\
\hline & $\begin{array}{l}\text { Regression } \\
\text { coefficient }\end{array}$ & S.E. & $P$-value & $\begin{array}{l}\text { Regression } \\
\text { coefficient }\end{array}$ & S.E. & $P$-value & $\begin{array}{l}\text { Regression } \\
\text { coefficient }\end{array}$ & S.E. & $P$-value \\
\hline Intercept & 55.4 & 4.8 & $<0.0001$ & 46.9 & 4.8 & $<0.0001$ & 33.5 & 6.6 & $<0.0001$ \\
\hline \multicolumn{10}{|l|}{ Age (years) } \\
\hline$\geq 40$ vs. $<40$ & -6.0 & 3.6 & 0.1 & -7.4 & 3.6 & 0.05 & -10.1 & 4.9 & 0.06 \\
\hline \multicolumn{10}{|l|}{ Cigarette smoking } \\
\hline Yes vs. no & 0.3 & 4.2 & 0.9 & 2.1 & 4.3 & 0.6 & 0.2 & 5.9 & 0.9 \\
\hline TdGA (mg/g Cr) & 1.1 & 0.7 & 0.1 & 1.4 & 0.7 & 0.05 & 1.8 & 0.9 & 0.07 \\
\hline
\end{tabular}
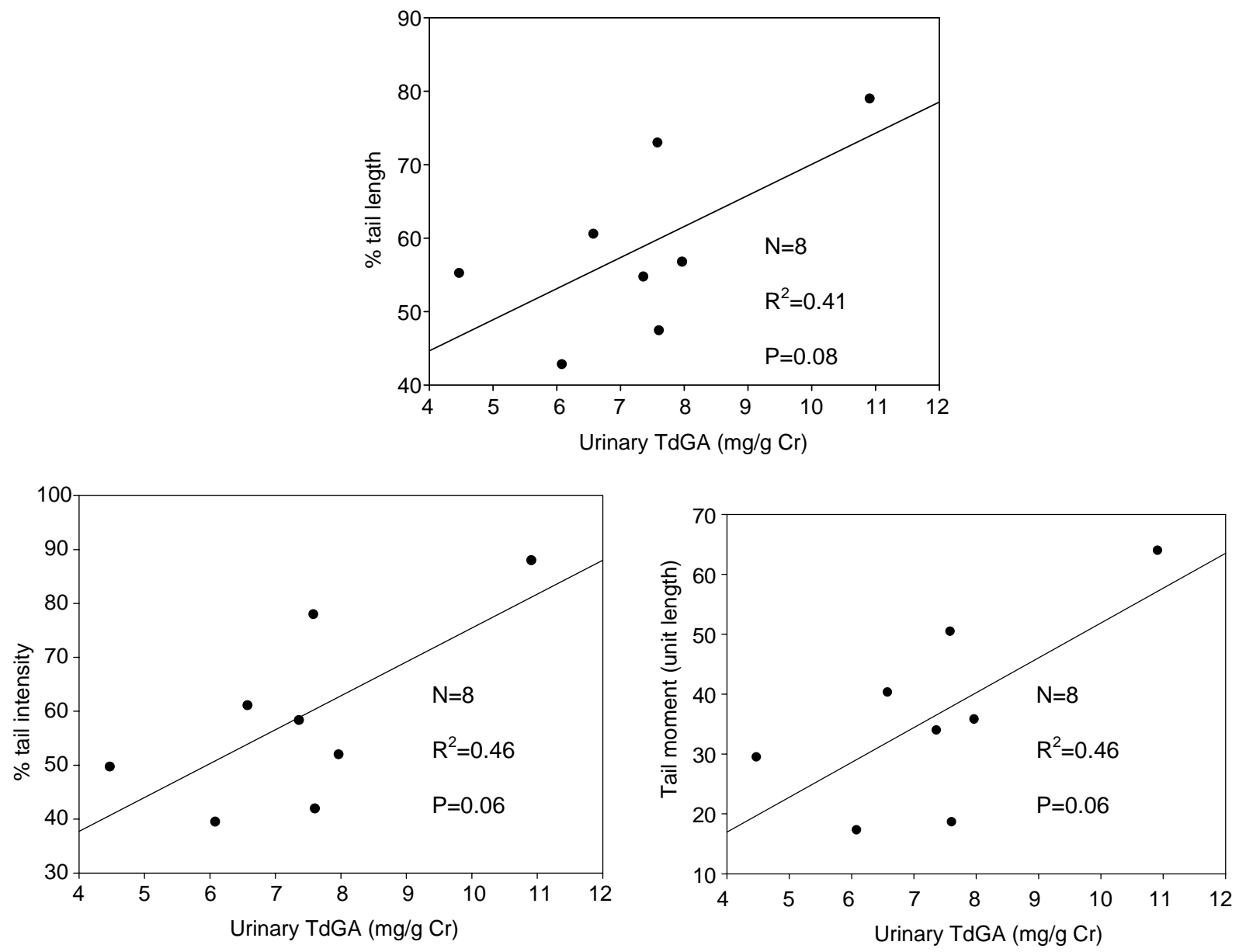

Fig. 1. DNA single strand breaks in peripheral lymphocytes at the end of shift and urinary TdGA at the commencement of the following shift. 
TdGA level $\left(r^{2}=0.47, P=0.06\right)$, similar results were obtained in tail intensity $\left(r^{2}=0.47, P=0.06\right)$.

\section{Discussion}

The results revealed that urinary TdGA level was significantly associated with DNA single strand breaks in peripheral lymphocytes in PVC workers. The dose-response relationship was particularly significant in workers who were estimated experiencing air VCM exposure level greater than $5 \mathrm{ppm}$. However, the associations of smoking, duration of employment, alcohol, coffee and tea consumption with DNA damage were not detected in this study with a limited statistical power.

In our study, we found a worker with TdGA level of $10.9 \mathrm{mg} / \mathrm{g} \mathrm{Cr}$ had significant impact on the statistic analysis. Thus, this subject's life style and work history were further reviewed. We found he was a current smoker who smoked about 10 cigarettes per day. The average amount of cigarette smoked was 20 cigarettes per day in smokers. This worker also had no history of consumption of alcohol, tea, coffee and vitamin. It seems life style would not play an important role in comet tail values in this worker. Further, this worker had worked as a tank cleaner and polymerization operator for 3 years and had the highest air sampling VCM level of $13.38 \mathrm{ppm}$ in our study subjects. We believed that the urinary TdGA level of this worker was highly correlated with air VCM exposure, and this might result in greater DNA single strand breaks.

Association between urinary TdGA and DNA single strand breaks indicates that VCM exposure may cause DNA damage. VCM is metabolized into active chloroethelene oxide (CEO) and chloroacetaldehyde (CAA), which can bind with DNA to form ethenoadduct [24]. These adducts may be repaired through base excision repair by glycosylase to form apuric site [25]. This apuric site is then transformed into single strand breaks in alkaline solution and detected by comet assay [18].

We found that workers with estimated air VCM level greater than $5 \mathrm{ppm}$ had higher DNA single strand breaks than those below $5 \mathrm{ppm}$. However, those with air VCM exposure between 1 and 5 ppm exposure did not show increased DNA single strand breaks. Previous studies have showed lower or no effect of CA after the air VCM level was reduced to $<5 \mathrm{ppm}$ [15]. SCE was also not detected from workers exposed to VCM at $<5 \mathrm{ppm}$ [16]. Such levels do not cause an increase DNA damage was confirmed by several studies [26]. Our result further confirms previous study. Comet assay may not be sensitive enough to detect the DNA damage resulted from air VCM level below $5 \mathrm{ppm}$.

In addition, a previous study reported that level of DNA single strand breaks was associated with duration of employment, which may be due to the accumulation of VCM-induced ethenoadduct [14]. In our study, we did not have similar finding. Previous study reported that increased DNA single strand breaks were found only in PVC workers who had VCM exposure 1 day before the specimen collection [13]. An animal study showed that $80 \%$ of DNA damage was repaired after $20 \mathrm{~h}$ post-exposure in mice exposed to VCM for $24 \mathrm{~h}$ [27]. Recent study also suggested that single strand breaks reflect most recent exposure [18]. In this study, urine samples were collected at the commencement of the following work shift, and the blood drawn at the end of the shift. The comprehensive study design is more likely to reflect the true association between the VCM exposure and DNA damage, and may avoid the problem of continuous repair of single strand breaks in peripheral lymphocytes.

The relationship between age and DNA single strand breaks has not been consistent [28-30]. One study reported that individuals older than 60 years had higher DNA damage as compared to the individuals younger than 60 years [31]. However, no age-related effects on the level of DNA damage were observed in several population-based studies [29,32]. In the current study, workers younger than 40 years revealed higher level of DNA damage as compared to the older workers. This observation may be caused by potential confounding factors. Our recent work indicated that active inflammation of hepatitis B and $\mathrm{C}$ was associated with increased ROS and subsequent 8-OhdG formation, which may contribute to the formation of DNA single strand breaks [33]. Unfortunately, hepatitis B and C virus infection status among these workers were not available in this study. Further studies are needed to clarify the relationship between age and DNA damage.

In this study, we did not observe effects of smoking on DNA single strand breaks. Relationship of smoking and DNA single strand breaks has been inconsistent 
[18]. Recent occupational studies reported no significant influence of smoking on comet parameters in either occupationally exposed groups or controls [34,35]. However, one study suggested smoking had a significant effect on DNA single strand breaks in the control group whereas no effect was noticed in the lead exposed workers [36]. Interestingly, a recent study conducted in a non-occupational group reported that significant difference of DNA single strand break was observed amongst the smokers and non-smokers [37]. It seems that occupational exposure may mask the effect of cigarette smoking-induced DNA single strand breaks. Thus, the failure to show effects of smoking in our study could be due to small sample size, or the interference of VCM exposure on the comet parameters. More studies are needed to clarify the role of smoking in DNA single strand breaks.

We concluded that air VCM exposure greater than $5 \mathrm{ppm}$ could induce DNA damage. The dose-response relationship of urinary TdGA level and DNA single strand breaks was particularly significant among the workers with $4 \mathrm{mg} / \mathrm{g} \mathrm{Cr}$ of urinary TdGA level, which is equivalent to $5 \mathrm{ppm}$ air VCM level. Further sensitive assay should be developed for the diction of DNA damage when air VCM exposure below $5 \mathrm{ppm}$.

\section{Acknowledgements}

Authors thank Miss Y.-F. Huang for technical assistance. This work is partly supported by NSC grant NSC-91-2320B-002-162.

\section{References}

[1] K.A. Mundt, L.D. Dell, R.P. Austin, R.S. Luippold, R. Noess, C. Bigelow, Historical cohort study of 10109 men in the North American vinyl chloride industry, 1942-1972: update of cancer mortality to 31 December 1995, Occup. Environ. Med. 57 (2000) 774-781.

[2] E. Ward, P. Boffetta, A. Anderson, D. Colin, C. Pietro, J.A. Deddens, M.D. Santis, G. Engholm, L. Hagmar, S. Langard, I. Lundberg, D. McElvenny, P. Roberta, D. Sali, L. Simonato, Update of the follow-up of mortality and cancer incidence among European workers employed in the vinyl chloride industry, Epidemiology 12 (2001) 710-718.

[3] R.H. Wong, P.C. Chen, C.L. Du, J.D. Wang, T.J. Cheng, An increased standardised mortality ratio for liver cancer among polyvinyl chloride workers in Taiwan, Occup. Environ. Med. 59 (2002) 405-409.
[4] A.K. Giri, Genetic toxicology of vinyl chloride-a review, Mutat. Res. 339 (1995) 1-14.

[5] R.H. Wong, J.D. Wang, L.L. Hsieh, C.L. Du, T.J. Cheng, Effects on sister chromatid exchange frequency of aldehyde dehydrogenase 2 genotype and smoking in vinyl chloride workers, Mutat. Res. 420 (1998) 99-107.

[6] IPCS, Environmental Health Criteria 215: Vinyl Chloride, International Programme on Chemical Safety, World Health Organization, Geneva, pp. 131-231.

[7] B.R. Pettit, G.S. King, V.G. Oberholzer, G.W. Lynes, H.K. Wilson, Thiodiglycollic acid in neonatal urine: an indication of novel metabolism, not toxic exposure to vinyl chloride, Lancet 2 (1984) 359.

[8] T.J. Cheng, Y.F. Huang, Y.C. Ma, Urinary thiodiglycolic acid levels for vinyl chloride monomer-exposed polyvinyl chloride workers, J. Occup. Environ. Med. 43 (2001) 934-938.

[9] M. Heger, G. Muller, K. Norporth, Investigations on the correlation between vinyl chloride (VCM)-uptake and excretion of its metabolites by $15 \mathrm{VCM}$-exposed workers. II. Measurements of the urinary excretion of the VCM-metabolite thiodiglycolic acid, Int. Arch. Occup. Environ. Health 50 (1982) 187-196.

[10] Z.Y. Chen, X.R. Gu, M.Z. Cui, X.X. Zhu, Sensitive flame-photometric-detector analysis of thiodiglycolic acid in urine as a biological monitor of vinyl chloride, Int. Arch. Occup. Environ. Health 52 (1983) 281-284.

[11] J.P. Payan, D. Beydon, J.P. Fabry, M.T. Brondeau, M. Ban, J. Ceaurriz, Urinary thiodiglycolic acid and thioether excretion in male rats dosed with 1,2-dichloroethane, J. Appl. Toxicol. 13 (1993) 417-422.

[12] M.J. McKenna, J.A. Zempel, E.O. Madrid, W.H. Braun, P.J. Gehring, Metabolism and pharmacokinetic profile of vinylidene chloride in rats following oral administration, Toxicol. Appl. Pharmacol. 45 (3) (1978) 821-835.

[13] C.L. Du, M.L. Kuo, H.L. Chang, T.J. Sheu, J.D. Wang, Changes in lymphocyte single strand breakage and liver function of workers exposed to vinyl chloride monomer, Toxicol. Lett. 77 (1995) 379-385.

[14] W.M. Awara, S.H. Ei-Nabi, M. Ei-Gohary, Assessment of vinyl chloride-induced DNA damage in lymphocyte of plastic industry workers using a single-cell gel electrophoresis technique, Toxicology 128 (1998) 9-16.

[15] A. Fucic, D. Barkovic, V. Garaj-Vrhovac, D. Barkovic, D. Kubelka, B. Ivanic, T. Dabo, A. Mijic, A nine-year follow up study of a population occupationally exposed to vinyl chloride monomer, Mutat. Res. 361 (1996) 49-53.

[16] B. Sinues, A. Sanz, M.L. Bermal, A. Tres, A. Alcala, J. Lanuza, C. Ceballos, M.A. Saenz, Sister chromatid exchanges, proliferating rate index, and micronuclei in biomonitoring of internal exposure to vinyl chloride monomer in plastic industry workers, Toxicol. Appl. Pharmocol. 108 (1991) 3745.

[17] A. Fucic, V. Garaj-Vrhovac, D. Barkovic, D. Kubelka, The sensitivity of the micronucleus assay for the detection of occupational exposure to vinyl chloride monomer, Mutat. Res. 325 (1994) 53-56.

[18] P. Moller, L.E. Knudsen, S. Loft, H. Wallin, The comet assay as a rapid test in biomonitoring occupational exposure 
to DNA-damage agents and effect of confounding factors, Cancer Epidemiol. Biomakers Prev. 9 (2000) 1005-1015.

[19] J.L. He, W.L. Chen, L.F. Jin, Comparative evaluation of the in vitro micronucleus test and the comet assay for the detection of genotoxic effects of X-ray radiation, Mutat. Res. 469 (2000) 223-231.

[20] M. Pitarque, A. Creus, R. Marcos, J.A. Hughes, D.J. Anderson, Examination of Various biomarkers measuring genotoxic endpoints from Barcelona airport personnel, Mutat. Res. 440 (1999) 195-204.

[21] T.J. Cheng, H.P. Kao, C.C. Chang, Effects of ozone and DNA single-strand breaks and 8-oxoguanine formation in A549 cells, Environ. Res. 93 (2003) 279-284.

[22] M. De Boeck, N. Touil, G. De Visscher, P.A. Vande, M. Kirsch-Volders, Validation and implementation of an internal standard in comet assay analysis, Mutat. Res. 469 (2000) 181-197.

[23] S. Ma, W.P. Chang, R.H. Fang, Measure of radiation-induced DNA double-strand breaks in human diploid fibroblasts from keloid and normal skin by single-cell gel electrophoresis, Plast. Reconstr. Surg. 98 (1996) 821-826.

[24] F.P. Guengerich, Roles of the vinyl chloride oxidation products 1-chlorooxirane and 2-chloroacetaldehyde in the in vitro formation of etheno adducts of nucleic acid bases, Chem. Res. Toxicol. 5 (1992) 2-5.

[25] M.K. Dosanjh, A. Chenna, E. Kim, H. Fraenkel-Conrat, L. Samson, B. Singer, All four known cyclic adducts formed in DNA by the vinyl chloride metabolite chloroacetaldehyde are released by a human DNA glycosylase, Proc. Natl. Acad. Sci. U.S.A. 91 (1994) 1024-1028.

[26] D. Anderson, C.R. Richardson, I.F. Purchase, H.J. Evans, M.L. O'Riordan, Chromosomal analysis in vinyl chloride exposed workers: comparison of the standard technique with the sister-chromatid exchange technique, Mutat. Res. 83 (1981) 137-144.

[27] S.A.S. Walles, B. Holmberg, Induction of single-strand breaks in DNA of mice after inhalation of vinyl chloride, Cancer Lett. 25 (1984) 13-18.
[28] A. Dhawan, N. Mathur, P.K. Deth, The effect of smoking and eating habits on DNA damage in Indian population as measured in the comet assay, Mutat. Res. 474 (2001) 121128.

[29] C. Betti, T. Davini, L. Giannessi, N. Loptieno, R. Barale, Comparative studies by comet test and SCE analysis in human lymphocytes from 200 healthy subjects, Mutat. Res. 343 (1995) 201-207.

[30] C. Andreoli, P. Leopardi, R. Crebelli, Detection of DNA damage in human lymphocytes by alkaline single cell gel electrophoresis after exposure to benzene or benzene metabolites, Mutat. Res. 377 (1997) 95-104.

[31] N.P. Singh, D.B. Danner, R.R. Tice, J.D. Pearson, L.J. Brant, C.H. Morrell, E.L. Schneider, Basal DNA damage in individual human lymphocytes with age, Mutat. Res. 256 (1991) 1-6.

[32] G. Frenzilli, C. Betti, T. Davini, M. Desideri, E. Fornai, L. Giannessi, F. Maggiorelli, P. Paoletti, R. Barale, Evaluation of DNA damage in leukocytes of ex-smokers by single cell gel electrophoresis, Mutat. Res. 375 (1997) 117-123.

[33] R.H. Wong, C.Y. Yeh, Y.M. Hsueh, J.D. Wang, Y.C. Lei, T.J. Cheng, Association of hepatitis virus infection, alcohol consumption and plasma Vitamin A levels with urinary 8-hydroxydeoxyguanosine in chemical workers, Mutat. Res. 535 (2003) 181-186.

[34] K. Danadevi, R. Rozati, B.S. Banu, P. Grover, Genotoxic evaluation of welders occupationally exposed to chromium and nickel using the comet and micronucleus assays, Mutagenesis 19 (2004) 35-41.

[35] J. Palus, K. Rydzynski, E. Dziubaltowska, K. Wyszynska, A.T. Natarajan, R. Nilsson, Genotoxic effects of occupational exposure to lead and cadmium, Mutat. Res. 540 (2003) 19-28.

[36] K. Danadevi, R. Rozati, B.B. Saleha, R.P. Hanumanth, P. Grover, DNA damage in workers exposed to lead using comet assay, Toxicology 187 (2003) 183-193.

[37] G. Speit, T. Witton-Davies, W. Heepchantree, K. Trenz, H. Hoffmann, Investigations on the effect of cigarette smoking in the comet assay, Mutat. Res. 542 (2003) 33-42. 